\title{
THE RELATIONSHIP OF PARTICIPATION MOTIVATION TO GOAL ORIENTATIONS AND PERCEIVED PHYSICAL ABILITY IN BRAZILIAN SWIMMERS
}

\author{
Afranio de ANDRADE ${ }^{1)}$, \\ ${ }^{1)}$ Federal University of Sergipe, Brazil, \\ Alfonso SALGUERO' ${ }^{2}$, René GONZALEZ-BOTO²), \\ and \\ Sara MÁRQUEZ ${ }^{2}$ \\ ${ }^{2)}$ University of León, Spain
}

\begin{abstract}
The relationships of achievement participation motivation, goal orientations and perceived physical ability were investigated in young competitive Brazilian swimmers. Four hundred and twenty five swimmers (287 males and 138 females, ranging in age from 11 to 25 years) completed the Participation Motivation Inventory (PMI), the Task and Ego Orientation in Sport Questionnaire (TEOSQ), and the Perceived Physical Ability Scale (PPA). Findings provided evidence for the validity and reliability of the questionnaires. Regression analyses showed that ego orientation predicted motives for participation related to status and fitness. In contrast, task orientation predicted motivational variables related with competition, energy release and skills/health. Perceived physical ability predicted variables with different degrees of self-determination.
\end{abstract}

Key words: participation motivation, goal orientations, perceived ability, swimming

Participation in organized youth sport is an accepted part of childhood development in western countries (Buonamano, Cei, \& Mussino, 1995; Gill, Gross, \& Huddleston, 1983). The sport participation motivation literature has focused on reasons why people (particularly children) engage in sport and/or discontinue their athletic participation (Gould, Feltz, \& Weiss, 1985). Although the same primary motives for sport participation do not emerge in all studies, data obtained have shown the presence of a fairly consistent set of motivational factors, including the development of skill, affiliation, status, the desire to be part of a team/group, competition or fitness (Salguero, González-Boto, Tuero, \& Márquez, 2003).

Simple description of motives, however, will not necessarily provide information about how young people view the sport experience, and further exploration of motivation is required using a theoretical approach (Zahariadis \& Biddle, 2000). Weiss and Chaumeton (1992) have proposed a motivational orientation framework to study

Correspondence concerning this article should be addressed to Sara Márquez, Faculty of Physical Activity and Sport Sciences, University of León, 24071 León, Spain (e-mail: sara.marquez@unileon.es). 
participation motivation in youth sport, considering motivation as an individual difference factor, in which individuals have different perceptions and behaviors due to their different motivational features. The achievement goal theory, which has become the most important conceptual avenue to address motivation in sport and physical education (Roberts, 2001), postulates that there are two primarily motivational goal orientations (task and ego orientations), which are determined based on peoples' beliefs on the determinants of their success and how they build their confidence (Nicholls, 1989). With a task goal, individuals are oriented toward developing new skills, trying to understand their practice, improving their level of competence, or achieving a sense of mastery. In contrasts central to an ego goal is a focus on one's ability and sense of self-worth. Goal perspective theory implies that dispositional achievement goal orientations influence sport motivation. Research suggests that task-oriented subjects are more satisfied and interested in practicing and enjoying sport than are ego-oriented subjects (Duda, Chi, Newton, Walling, \& Catley, 1995). White and Duda (1994), in their study of youth, intercollegiate, and recreational sport participants, found that task orientation was associated with the more intrinsic motives for involvement such as skill development and enhancing one's level of fitness. In contrast, ego orientation was linked to extrinsic motives for participation such as social recognition and increasing one's social status. Papaioannou \& McDonald (1994) reported similar results in a study with Greek students participating in physical education classes. Nevertheless, results from research linking the two set of constructs are not always consistent with predictions from the theory of achievement motivation, and in student athletes both ego orientation and task orientation have been reported to correlate positively with Competition and Social participation motives (Kozloff, 2004). Complementary to the theory of achievement motivation is the selfdetermination theory in sport (Deci \& Ryan, 1985), which proposed a self-determination continuum to describe motivational variables, from intrinsically motivated behavior, with the highest self-determination, and occurring without the incentive of external rewards, to external regulation, with behaviors regulated through external means. Deci and Ryan (1991) argued that factors which satisfy the needs for autonomy and relatedness will promote self-determined types of motivation. According to Ntoumanis (2001), task orientation can fulfill these needs, and therefore, can enhance self-determined motivation. In contrast, high ego orientation would not be conductive to the satisfaction of those needs.

A part of achievement motivation research has focused on the relationship between goal orientations and conceptually related variables such as motivation without accounting for participant's perceptions of competence. Both the achievement motivation and the self-determination theory underline the role of perceived competence in guiding achievement behavior. According to the achievement motivation theory, individuals with high ego orientation and high perceived competence are likely to be driven in sport by rewards and external recognition and not by their desire to work hard and learn new skills (Nichols, 1989; Hardy, 1997). Deci and Ryan (1985) argued that high perceived competence leads to self-determined types of motivation only under conditions of autonomy, which are not likely to exist in individuals with high ego orientation. The 
empirical link between both theories has been examined by Ntoumanis (2001), who observed in a sample of British students that task orientation predicted intrinsic motivation, ego orientation predicted motivational variables with low self-determination, and perceived competence was positively related to both self-determined motivation and external regulation.

Although much is known about motives for people to engage in physical activity and exercise, there is little information about possible differences in these motives and their predictor factors across countries and cultures (Duda \& Allison, 1990). To date, participation motivation and the meaningfulness of the concept of goal perspectives have not been examined among Brazilian athletes. The purpose of this research was to analyze the relationship between the motives for participation, the goal orientation and the athlete's perception of physical ability in a sample of young Brazilian swimmers, and to investigate whether differences with previous studies appear. It is hypothesized that ego orientation would be positively associated with less self-determined motivational variables and task orientation with a more intrinsically motivated behavior, while perceived physical ability would be associated to a larger set of motivational variables. An additional objective was to provide psychometric evidence for the validity and reliability of the Portuguese versions of different established measures. Finally, because there is evidence in the literature that males and females have different achievement motivation patterns (White, Kavussanu, \& Guest, 1998; Gano-Overway, \& Duda, 2001), we investigated whether differences related to gender and other factors, such as age and level of competition, existed in goal orientations, and could influence the relationship with participation motivation and perceived physical ability.

\section{METHOD}

Participants. The participants were recruited through the auspices of the Brazilian Swimming Federation. Aquatic directors and coaches agreed to participate in the study and to recruit swimmers from their teams. Data were obtained on a voluntary basis, after written consent had been signed, from 425 participants (287 males and 138 females), aged 11 yrs to $25 \mathrm{yrs}(M=17, S D=3)$. Parents of participants younger than 18 were given a summary of the study and were asked to give their permission for their children's participation. Swimmers came from 22 different clubs, and competed at a local $(N=141)$, regional $(N=167)$ or national $(N=117)$ level.

Instruments. The scales were translated by the parallel back-translation procedure by individuals that were familiar with motivation studies in sport. The English scale was translated into Portuguese by a bilingual individual and the Portuguese version was translated back into English without the aid of the English scale by a second individual. Then, modifications were made upon agreement of both translators. Finally the scale was examined by coaches that were asked to suggest changes to the wording of the items and the directions for responding to them. No modifications were suggested.

Each participant responded to the Portuguese versions of the Task and Ego Orientation in Sport Questionnaire (TEOSQ) (Duda \& Whitehead, 1998), the Participation Motivation Inventory (PMI) (Gill et al., 1983, Gould et al., 1985) and the Perceived Physical Ability Scale (PPA) (Ryckman, Robbins, Thornton, \& Cantrell, 1982). The TEOSQ assesses disposition towards task and ego achievement goal orientations and elicits scores on task (7 items) and ego (6 items) orientation through the stem from "I feel most successful in sport when ...". Each item was answered on a 5-point Likert scale ranging from 1 ("strongly disagree") to 5 ("strongly agree"). The PMI consists of a list a 32 possible reasons for participating in sports. Respondents 
were asked to indicate their preferences in a Likert type scale from 1 ("not at all important") to 5 ("extremely important"). The PPA assesses perceived physical ability and consists of 10 six-point Likert items ranging from 1 ("strongly disagree") to 5 ("strongly agree"). According to previous suggestions by different authors, a second scale, including six items specific for swimming, was added to the general scale of the PPA (Mc Auley \& Gill, 1983; Salguero, González-Boto, Tuero, \& Márquez, 2004).

In addition, participants were asked to complete a questionnaire assessing demographic information such as gender, age, and level of competitive sport experience.

Procedures. The swimmers were asked to meet with the researchers in a meeting room away from the pool deck at a time other than the regular workout time. At that meeting, researchers described the nature of the study and administered the questionnaires to the participants. The researchers helped the younger children to interpret the questionnaire when necessary. Questionnaires were administered at approximately the half way mark of the seasons. Assurance that all data would be kept strictly confidential was given. Participants were asked to answer each item as honestly as possible.

Data analysis. A factor analysis with oblique factor rotations was performed using the responses from the questionnaires. Factor scales reliabilities were assessed using coefficient alpha. Zero-order relationships between motives for participation, goal orientations and perceived physical ability were examined by Pearson's correlation coefficients. Moderate hierarchical regression analyses (Aiken \& West, 1991) were carried out to assess predictability of motives for participation by goal orientations and perceived physical activity. In each of the regressions, goal orientations and perceived physical ability were first entered individually to ascertain their unique contribution. Next three two-way interactions-ego orientation $\times$ perceived physical ability, task orientation $\times$ perceived physical ability, and task orientation $\times$ ego orientation - were entered individually. Finally the three-way interaction term of these variables was entered in the last step. In order to determine whether goal orientations differed by gender or level of competition, scores for all items were used as dependent variables in a 2 (gender) $\times 3$ (level of competition) MANCOVA, with age as covariate (Tabachnick \& Fidell, 2000; Stevens, 1992). An alpha level of .05 was used for all statistical tests.

\section{RESULTS}

Psychometric properties of scales and descriptive statistics. The factor structure of the PMI was analyzed by factor analysis with oblique rotation. Item and factor were selected by the criteria of factor loadings above .40 and eigenvalues above 1.0 (Tabachnick \& Fidell, 2000; Stevens, 1992). Only two items, "Like to get out of the house" and "I like to do something I'm good at" that loaded less than .40 were eliminated from further consideration. Eight interpretable factors, which accounted for $57.1 \%$ of the total variance, were identified (Table 1). The eight factors were labeled Status, Team Atmosphere, Competition, Energy Release, Fitness, Significant Others, Affiliation and Skills/Health. The Cronbach alpha coefficients (Cronbach, 1951) from the different subscales ranged from .68 to .81 (Table 1), reaching or approaching the minimum level of acceptance (Nunnally, 1978). The factor structure of the TEOSQ was confirmed by the presence of two factors corresponding to task and ego orientations that accounted for $43.8 \%$ of the variance. Cronbach alpha coefficients for the task and ego subscales were satisfactory (task alpha $=.69$; ego alpha $=.79)($ Table 2$)$. Cronbach alpha for the PPA scale was .72.

Table 3 presents the means and standard deviations for all variables in the study. The results show that swimmers reported high scores in task orientation, Fitness, Skills/Health, Affiliation and Team Atmosphere, and moderate scores in perceived physical ability, ego orientation, Competition, Status, Energy Release and Significant Others. 
Table 1. Factor Analysis and Reliability of Factors for the PMI

\begin{tabular}{|c|c|c|c|c|c|c|c|c|c|}
\hline \multirow{2}{*}{ Item } & \multicolumn{9}{|c|}{ Factor loadings } \\
\hline & 1 & 2 & 3 & 4 & 5 & 6 & 7 & 8 & $\alpha$ \\
\hline Status & & & & & & & & & .81 \\
\hline Popular with others & .82 & & & & & & & & \\
\hline Like to feel important & .82 & & & & & & & & \\
\hline Want others to notice me & .74 & & & & & & & & \\
\hline Like to win & .45 & & & & & & & & \\
\hline Like the rewards & .42 & & & & & & & & \\
\hline Team atmosphere & & & & & & & & & .75 \\
\hline Like the team spirit & & .75 & & & & & & & \\
\hline Like being in a team & & .68 & & & & & & & \\
\hline Like the coaches & & .67 & & & & & & & \\
\hline Like the team work & & .58 & & & & & & & \\
\hline Competition & & & & & & & & & .72 \\
\hline Compete at higher levels & & & .74 & & & & & & \\
\hline Like to compete & & & .71 & & & & & & \\
\hline Like the challenge & & & .60 & & & & & & \\
\hline Like the excitement & & & .42 & & & & & & \\
\hline Energy release & & & & & & & & & .76 \\
\hline Like to get ride of energy & & & & .68 & & & & & \\
\hline Something to do & & & & .63 & & & & & \\
\hline To be active & & & & .57 & & & & & \\
\hline Like the action & & & & .50 & & & & & \\
\hline Like to exercise & & & & .47 & & & & & \\
\hline Fitness & & & & & & & & & .73 \\
\hline Get in shape or stronger & & & & & .73 & & & & \\
\hline How my body looks/feels & & & & & .71 & & & & \\
\hline To stay in shape & & & & & .69 & & & & \\
\hline Significant others & & & & & & & & & .70 \\
\hline Friends want me to participate & & & & & & .77 & & & \\
\hline Family wants me to participate & & & & & & .77 & & & \\
\hline Team dinners/picnics & & & & & & .48 & & & \\
\hline Affiliation & & & & & & & & & .78 \\
\hline Want to be with friends & & & & & & & .72 & & \\
\hline Like to meet friends & & & & & & & .65 & & \\
\hline Skills/Health & & & & & & & & & .68 \\
\hline Want to improve my skills & & & & & & & & .69 & \\
\hline To improve my health & & & & & & & & .68 & \\
\hline Want to learn new skills & & & & & & & & .54 & \\
\hline Eigenvalue & 8.71 & 2.43 & 2.16 & 1.71 & 1.40 & 1.39 & 1.11 & 1.04 & \\
\hline$\%$ of variance & 24.9 & 6.94 & 6.17 & 4.89 & 4.00 & 3.97 & 3.16 & 2.98 & \\
\hline
\end{tabular}


Table 2. Factor Analysis and Reliability of Factors for the TEOSQ

\begin{tabular}{|c|c|c|c|}
\hline \multirow{2}{*}{ Item } & \multicolumn{3}{|c|}{ Factor loadings } \\
\hline & 1 & 2 & $\alpha$ \\
\hline Ego & & & .79 \\
\hline I'm the best & .82 & & \\
\hline The others can't do as well as me & .74 & & \\
\hline I score the most goals & .71 & & \\
\hline I'm the only one who can do the play or skill & .70 & & \\
\hline Others mess up and I don't & .63 & & \\
\hline I can do better than my friends & .56 & & \\
\hline Task & & & .69 \\
\hline I learn something that is fun to do & & .88 & \\
\hline I learn a new skill and it makes me want to practice more & & .73 & \\
\hline I do my very best & & .72 & \\
\hline A skill I learn really feels right & & .70 & \\
\hline Something I learn makes me want to go to practice more & & .67 & \\
\hline I learn a new skill by trying hard & & .66 & \\
\hline I work really hard & & .51 & \\
\hline Eigenvalue & 3.60 & 2.07 & \\
\hline$\%$ of variance & 27.8 & 16.0 & \\
\hline
\end{tabular}

Table 3. Descriptive Statistics for the PMI, TEOSQ, and PPA Variables

\begin{tabular}{lll}
\hline & Mean & SD \\
\hline PMI & & \\
$\quad$ Status & 3.61 & 1.01 \\
Team atmosphere & 4.08 & 0.76 \\
Competition & 3.86 & 0.72 \\
Energy release & 3.71 & 0.67 \\
Fitness & 4.66 & 0.82 \\
Significant others & 3.34 & 0.95 \\
Affiliation & 4.25 & 0.85 \\
Skills/Health & 4.46 & 0.57 \\
TEOSQ & & \\
Ego & 2.43 & 0.87 \\
Task & 4.04 & 0.47 \\
PPA & & \\
Perceived ability & 2.79 & 0.50 \\
\hline
\end{tabular}


Table 4. Pearson Correlation Coefficients for the PMI, TEOSQ, and PPA Variables

\begin{tabular}{|c|c|c|c|c|c|c|c|c|c|c|}
\hline & $\begin{array}{c}\text { Team } \\
\text { atmosphere }\end{array}$ & Competition & $\begin{array}{l}\text { Energy } \\
\text { release }\end{array}$ & Fitness & $\begin{array}{l}\text { Significant } \\
\text { others }\end{array}$ & Affiliation & $\begin{array}{l}\text { Skills/ } \\
\text { Health }\end{array}$ & Ego & Task & $\begin{array}{l}\text { Perceived } \\
\text { Ability }\end{array}$ \\
\hline Status & $.31^{*}$ & $.50^{*}$ & $.41^{*}$ & $.29^{*}$ & $.37^{*}$ & $.32 *$ & $.40^{*}$ & $.20 *$ & .15 & $.27 *$ \\
\hline $\begin{array}{l}\text { Team } \\
\text { atmosphere }\end{array}$ & & $.39 *$ & $.40^{*}$ & .13 & $.33^{*}$ & $.56^{*}$ & $.51^{*}$ & $-.16^{*}$ & .09 & $.26^{*}$ \\
\hline Competition & & & $.45^{*}$ & .12 & .09 & $.38^{*}$ & $.48^{*}$ & $.19^{*}$ & $.33 *$ & $.45^{*}$ \\
\hline $\begin{array}{c}\text { Energy } \\
\text { release }\end{array}$ & & & & $.18^{*}$ & $.48^{*}$ & $.47 *$ & $.42 *$ & .14 & $.21^{*}$ & $.34 *$ \\
\hline Fitness & & & & & .12 & .06 & .12 & $.22 *$ & -.03 & $.20 *$ \\
\hline $\begin{array}{l}\text { Significant } \\
\text { others }\end{array}$ & & & & & & $.30^{*}$ & $.40^{*}$ & .11 & .10 & $.29 *$ \\
\hline Affiliation & & & & & & & $.42 *$ & -.02 & $.17^{*}$ & .13 \\
\hline Skills/Health & & & & & & & & .15 & $.21^{*}$ & $.43 *$ \\
\hline Ego & & & & & & & & & & $.19^{*}$ \\
\hline
\end{tabular}

$* p<.05$

Zero-order relationships between motives for participation, goal orientations and perceived physical ability. Variables interrelationships were analyzed by Pearson's correlation coefficients (Table 4). Energy Release, Competition, Skills/Health and Affiliation were positively related to task orientation, whereas Status and Fitness were positively related and Team Atmosphere negatively related to ego orientation. Both goal orientations and all motivation scales, except Affiliation, were positively related to perceived physical ability. A positive relation was also observed between task orientation and ego orientation.

Hierarchical regression analyses. We conducted hierarchical regression analysis to determine whether motives for participation are best predicted by goal orientations, and perceived physical ability. As Table 5, which display statistics when all the predictors and interactions were entered in the equation, indicates, there were several significant main effects. Competition, Energy Release and Skills/Health were positively predicted by task orientation and perceived physical activity. Ego orientation and perceived physical ability were positive predictors of Status and Fitness. Ego orientation emerged as a negative predictor of Team Atmosphere. Lastly, Team Atmosphere and Significant Others were positively predicted by perceived physical ability. One two-way interaction was significant: Team Atmosphere was predicted by the interaction between task and ego orientations.

Gender, level of competition, age and goal orientations. To analyze gender, level of competition and age differences in goal orientations, a 2 (subject Gender) $\times 3$ (Level of Competition) MANCOVA, with age as covariate, was conducted. The effect of the covariate itself was non-significant (Ego: $F(12,266)=.01, p=.99$; Task: $F(12,266)=.05$, $p=.82$ ) and the model could thus be reduced to a simple MANOVA. No significant multivariate effect emerged for gender $($ Ego: $F(12,266)=.11, p=.74$; Task: $F(12,266)=$ 
Table 5. Hierarchical Regression Analyses

\begin{tabular}{lcccc}
\hline \multicolumn{1}{c}{ Predictors } & $\mathrm{R}^{2}$ change & F change & $\beta$ & $\mathrm{t}$ \\
\hline Status & & & & \\
Ego Orientation & .03 & $7.9^{*}$ & .20 & $2.46^{*}$ \\
Perceived Ability & .06 & $14.7^{* *}$ & .31 & $3.84^{* *}$ \\
Team Atmosphere & & & & \\
Ego Orientation & .02 & $6.3^{*}$ & -.22 & $-2.55^{*}$ \\
Perceived Ability & .04 & $11.2^{* *}$ & .23 & $2.81^{* *}$ \\
Ego $\times$ Task Orientation & .02 & $3.5^{*}$ & .15 & $2.01^{*}$ \\
Competition & & & & \\
Task Orientation & .03 & $10.8^{*}$ & .22 & $2.60^{*}$ \\
Perceived Ability & .06 & $21.3^{* *}$ & .30 & $3.70^{* *}$ \\
Energy Release & & & & \\
Task Orientation & .02 & $5.8^{*}$ & .20 & $2.40^{*}$ \\
Perceived Ability & .05 & $13.0^{* *}$ & .36 & $4.46^{* *}$ \\
Fitness & & & & \\
Ego Orientation & .02 & $7.2^{*}$ & .22 & $2.61^{*}$ \\
Perceived Ability & .04 & $11.7^{* *}$ & .27 & $3.16^{* *}$ \\
Significant Others & & & .32 & \\
Perceived Ability & .06 & 17.9 & .34 & $4.03^{* *}$ \\
Skills/Health & & & & \\
Task Orientation & .06 & & .18 & \\
Perceived Ability & & & & \\
\hline
\end{tabular}

$* p<.05, * * p<.01$

$.03, p=.87)$ or level of competition $($ Ego: $F(12,266)=.19, p=.97$; Task: $F(12,266)=.19$, $p=.97)$, and no significant interaction was observed $($ Ego: $F(12,266)=.35, p=.87$; Task: $F(12,266)=.41, p=.84)$

\section{DISCUSSION}

Factor analysis of the PMI identified a set of motivational factors with an acceptable reliability, and consistent with those described in previous investigations. Affiliation, Energy Release, Status, Competition, Team or Fitness are factors found in most studies (Brodkin \& Weiss, 1990; Buonamano et al., 1995; Salguero et al., 2003), apparently indicating that dimensions associated with motivation participation are generally similar 
across cultures, and supporting the notion that youth not only subscribe to excitement and competence, but also to skill and social motives (Sit \& Lindner, 2005). Data also supported the validity and reliability of the Portuguese form of the TEOSQ, and correlations of the scores on the different PMI subscales with task and ego orientations, provided some evidence for its construct validity, because scores on the task orientation scale had higher correlations with Competition or Energy Release, while ego orientation correlated more highly with Status or Fitness. Finally, the PPA scale had a reasonable reliability, and a good convergent validity, because it correlated more strongly with Competition, Skills and Energy Release than with any of the other motivation participation factors (White \& Duda, 1994).

Pearson's correlation coefficients provided information about the variables interrelationships. An interesting result of the analysis was the relationship observed between task and ego orientation. Even though the strength of the relationship was small and similar to that previously reported in English schoolchildren (Zahariadis \& Biddle, 2000), results were not completely consistent with Nicholls' (1989) notions about the orthogonality of task and ego orientations. A high negative relationship has been found in a study of intercollegiate Thai athletes (Li, Harmer, Chi, \& Vongjaturapat, 1997), and a clearly positive relationship detected in a Korean sport setting (Kim, 1995), which suggests that the relationship between the two goal orientations may vary as a result of the interaction of factors such as levels of sport participation and culture. In fact, in our study an interactive effect between ego orientation and task orientation was observed in the prediction of team atmosphere as a motivational factor.

Competition, Energy Release, Skills/Health and Affiliation were positively related to task orientation, whereas Status and Fitness motives were related to ego orientation. Results of the hierarchical regression analysis partially supported zero-order relationships, and showed that task orientation predicted motivational variables related with Competition, Energy Release and Skills/Health, while ego orientation emerged as a positive predictor of Status and Fitness. This is in accordance with the goal perspective and the self-determination theories, because it is presumed that for a task-oriented person interest in the activity rather that the outcome of the activity is most pertinent, and a taskinvolved goal perspective should be positively related to dimensions of intrinsic motivation and high self-determination. On the contrary, a relationship with a less selfdetermined motivation, as is the case for the Status factor, is mainly expected for ego orientation, because the personal satisfaction that can stem from task mastery is secondary and more importance is given to the competitive outcome (Dweck, 1985; Duda et al., 1995). Results are also consistent with data by Ntoumanis (2001), indicating that task orientation predicts intrinsic motivational variables with high-self determination, and with a recent study by Sit and Lindner (2005) in which high task orientation was found to be strongly linked to intrinsic-typed sport motives such as excitement/challenge, while ego orientation was found to be related to the status motive only.

Although different studies have investigated the relationship between participation motivation and perceived competence, results have not been altogether consistent. For example, Gould et al. (1985) found no differences in the importance attached to various 
motives between high and low ability swimmers, although an important limitation of this research comes from the fact that individual differences were defined by the coaches and not by the athletes themselves. In our study, the correlation analysis showed only moderate positive zero-order correlations between motives for participation and perceived physical ability, but these associations were consistent and in apparent accordance with the competence motivation theory and the self-determination theory. Thus, perceived physical ability was mainly related to factors such as Competition, Energy Release or Skills and was a positive predictor of these motivational factors. This is in agreement with the finding by Ryckman and Hammel (1993) that athletes higher in perceived physical ability generally rated as more important motivational factors without the incentive of external rewards or the report by Klint and Weiss (1986) that perceived competence differences are related to skill development. The present results also indicate that perceived physical ability was weakly associated with Status and positively predicted these motivational factors. This finding, which supports previous studies indicating that perceived competence may positively predict low self-determined types of motivation (Pelletier et al., 1995; Ntoumanis, 2001), also makes conceptual sense. A look at the items in the Status scale of the PMI indicate that participation is mainly determined the necessity of feeling important or being popular. Therefore, it could be expected that individuals with perceptions of high ability associate competence with these extrinsic outcomes. Fitness motives could be extrinsic if people are concerned about appearing good in other's eyes or intrinsic and highly self-determined if individuals exercise for the pleasure of building a healthy body. In both cases, a positive prediction by perceived ability could be expected, and this happened in the present study.

The only interactive effect of goal orientations on the different motivational factors corresponded to team atmosphere, which was also negatively predicted by ego orientation. This may be indicating that an adequate level of task orientation is required to safeguard team environment from the constant interindividual comparison promoted by ego orientation, which is unlikely to strengthen social links among athletes (Duda, 1992). The lack of interaction between task or ego orientation and perceived physical ability on types of motivation is difficult to explain. A similar finding has been previously reported by Ntoumanis (2001) in a sample of British students. In that case results were partly attributed to the high perceived competence of the participants and the reduced statistical power of the interaction effects. However, in the present research mean score of participants was 2.7 on a 5 point scale. Another possibility, that should require to be explored, is the potential mediating effect of autonomy on motivated behaviour.

An interesting result found in our study was the absence of a significant gender or level of competition differences with respect to goal orientations. There is considerable evidence to suggest that males and females have different achievement motivation patterns, with American males generally reporting higher levels of ego orientation that females, especially at higher levels of competitive involvement (White \& Duda, 1994; White, Kavussanu et al., 1998; Gano-Overway, \& Duda, 2001). This has been explained through the importance of the process of socialization, and the possibility that males, in their socialization history may have received more acknowledgements for winning and 
outperforming others (White, Kavussanu et al., 1998). Some findings are, however, contradictory to the research conducted with North American samples. Thus, Thai female athletes reported significantly higher ego orientation and lower task orientation when compared to their male counterparts (Li; Harmer, Acock, Vongjaturapat, \& Boonverabut, 1997), and lack of gender differences have been found when studying Korean athletes (Kim \& Gill, 1997), or American and Japanese physical education students (Isogai, Brewer, Cornelius, Etnier, \& Tokunaga, 2003). The fact that no significant difference was detected between male and female young Brazilian swimmers could reflect a sociocultural difference (Barroso Beltrao, Costa Gissoni, \& Feijo, 2002) or be a sample or sport-linked phenomenon, requiring in any case further investigation.

It should be noted that the present sample was markedly dissimilar to those that have been commonly employed in sport motivation research, because athletes originated from a developing South American country, whereas more traditional samples are made up of athletes from Western countries. Although this does not rule out the necessity of more research to ascertain the generality of the obtained results, the fact remains that the overall pattern of results is consistent with previous research. Nevertheless, the correlational design of the present study does not allow drawing any causal inference, and the relatively low variance explained underscores the fact that the relationship between motivation, goal orientation and perceived competence is a complex phenomenon and suggests the need for more refined analyses including multiple psychological as well as socio-cultural variables. Finally, from an applied point of view, it is important to consider that task oriented youth sport athletes are more likely to derive enjoyment out of participation and therefore, be less likely to dropout (White, Duda, \& Keller, 1998). Coaches need to promote intrinsic, self-determined forms of motivation, and an effort should be made to structure the swimming environment in order to enhance motivation through the promotion of a task orientation.

\section{REFERENCES}

Aiken, I. S., \& West, S. G. 1991. Multiple regression: testing and interpreting interactions. Newbury Park, CA: Sage.

Barroso Beltrao, E., Costa Gissoni, V., \& Feijo, O. G. 2002. How will professionally successful women from Rio de Janeiro perceive their own body. Fitness \& Performance, 1, 21-27.

Brodkin, P., \&Weiss, M. R. 1990. Developmental differences in motivation for participating in competitive swimming. Journal of Sport and Exercise Psychology, 12, 248-263.

Buonamano, R., Cei, A., \& Mussino, A. 1995. Participation motivation in Italian youth sport. Sport Psychology, 9, 265-281.

Cronbach, L. J. 1951. Coefficient alpha and the internal structure of tests. Psychometrica, 16, 297-333.

Deci, F. I., \& Ryan, F. M. 1985. Intrinsic motivation and self-determination in human behaviour. New York: Plenum Press.

Deci, F. I., \& Ryan, F. M. 1991. A motivational approach to self: Integration in personality. In R. Deinstbier (Ed.), Nebraska Symposium on motivation. Vol. 38: Perspectives in motivation. (pp. 237-288). Lincoln, NB: University of Nebraska Press.

Duda, J. L. 1992. Motivation in sport settings: A goal perspective approach. In G. C. Roberts (Ed.), Motivation in sport and exercise. (pp. 57-91). Champaign, IL: Human Kinetics. 
Duda, J. L., \& Allison, M. T. 1990. Cross-cultural analysis in exercise and sport psychology: a void in the field. Journal of Sport and ExercisePsychology, 12, 114-131.

Duda, J. L., Chi, L., Newton, M. L., Walling, M. D., \& Catley, D. 1995. Task and ego orientation and intrinsic motivation in sport. International Journal of Sport Psychology, 26, 40-63.

Duda, J. L., \& Whitehead, J. 1998. Measurement of goal perspectives in the physical domain. In: J. L. Duda (Ed.), Advances in sport and exercise psychology measurements. (pp. 21-48). Morgantown, WV: Fitness Information Technology.

Dweck, C. S. 1985. Intrinsic motivation, perceived control, and self-evaluation maintenance: an achievement goal analysis. In: C. Ames, \& R. Ames (Eds.), Research on motivation in education: The classroom milieu, Vol. 2. (pp. 289-305). Orlando, FL: Academic Press.

Gano-Overway, L. A., \& Duda, J. L. 2001. Personal theories of achievement motivation among African and White mainstrean American athletes. International Journal of Sport Psychology, 32, 35-54.

Gill, D. L., \& Gross, J. B., \& Huddleston, S. 1983. Participation motivation in youth sports. International Journal of Sport Psychology, 14, 1-14.

Gould, D., Feltz, D., \& Weiss, M. 1985. Motives for participating in competitive youth swimming. International Journal of Sport Psychology, 16, 126-140.

Hardy, L. 1997. The Coleman Roberts Griffith Address. Threee myths about applied consultancy work. Journal of Applied Sport Psychology, 9, 277-294.

Isogai, H., Brewer, B. W., Cornelius, A. E., Etneir, J., \& Tokunaga, M. 2003. A cross-cultural analysis of goal orientation in American and Japanese physical education students. International Journal of Sport Psychology, 34, 80-93.

Kim, B. J. 1995. Psychometric evaluation of the TEOSQ and the IMI in a Korean sport setting. Paper presented at the meeting of the North American Society for Psychology of Sport and Physical Activity, Monterey, CA.

Kim, B. G., \& Gill, D. L. 1997. A cross-cultural extension of goal perspective theory to Korean youth sport. Journal of Sport and Exercise Psychology, 19, 142-155.

Klint, K. A., \& Weiss, M. R. 1986. Dropping in and dropping out: participation motives of current and former youth gymnasts. Canadian Journal of Applied Sport Sciences, 11, 106-114.

Kozloff, D. A. 2004. Participation motivation and goal orientation of Division III student-athletes; Eugene, OR: Microform Publications, Institute for Sport \& Human Performance. Retrieved April 26, 2006, from http://kinpubs.uoregon.edu.

Li, F., Harmer, P., Acock, A., Vongjaturapat, N., \& Boonverabut, S. 1997. Testing the cross-cultural validity of TEOSQ and its factor covariance and mean structures across gender. International Journal of Sport Psychology, 28, 271-286.

Li, F.; Harmer, P., Chi, L., \& Vongjaturapat, N. 1997. Cross-cultural validation of the task and ego orientation in sport questionnaire. Journal of Sport and Exercise Psychology, 18, 392-407.

McAuley, E.. \& Gill, D. L. 1983. Reliability and validity of the physical self-efficacy scale in a competitive setting. Journal of Sport Psychology, 5, 410-418.

Nicholls, J. G. 1989. The competitive ethos and democratic education. Cambridge, MA: Harvard University Press.

Ntoumanis, N. 2001. Empirical links between achievement goal theory and self-determination theroy in sport. Journal of Sport Sciences, 19, 397-409.

Nunnally, J. C. 1987. Psychometric theory. New York: McGrawHill.

Papaioannou, A., \& McDonald, A. 1994. Goal perspectives and purpose of physical education as perceived by Greek adolescents. Psychology and Education Review, 16, 41-48.

Pelletier, L. G., Fortier, M. S., Vallerand, R. J., Tuson, K. M., Briere, N. M., \& Blais, M. R. 1995. Toward a new measure of intrinsic motivation, extrinsic motivation, and amotivation in sports: The Sports Motivation Scale (SMS). Journal of Personality and Social Psychology, 17, 35-53.

Roberts, G. 2001. Understanding the dynamics of motivation in physical activity: The influence of achievement goals on motivational processes. In: G.C. Roberts (Ed.), Advances in motivation in sport and exercise. (pp. 1-50), Champaign, IL: Human Kinetics.

Ryckman, R. M, \& Hammel, J. 1993. Perceived physical ability differences in the sport participation motives of young athletes. International Journal of Sport Psychology, 24, 270-283.

Ryckman, R. M., Robbins, M. A., Thornton, B., \& Cantrell, P. 1982. Development and validation of a 
physical self-efficacy scale. Journal of Personality and Social Psychology, 42, 891-900.

Salguero, A., González-Boto, R., Tuero, C., \& Márquez, S. 2003. Development of a Spanish version of the participation motivation inventory for young competitive swimmers. Perceptual \& Motor Skills, 96, 637-646.

Salguero, A., González-Boto, R., Tuero, C., \& Márquez, S. 2004. Relationship between perceived physical ability and sport participation motives in young competitive swimmers. Journal of Sports Medicine, 44, 294-299.

Stevens, J. (1992). Applied multivariate statistics for the social sciences. Hillsdale, NJ; 1992.

Sit, C. H. P., \& Lindner, K. J. 2005. Motivational orientations in youth sport participation: Using achievement goal theory and reversal theory. Personality and Differences, 38, 605-618.

Tabachnick, B. J., \& Fidell, L. S. 2000. Using multivariate statistics. Boston: Allyn \& Bacon.

Weiss, M. R., \& Chaumeton, N. 1992. Motivational orientations in sport. In H. S. Horn (Ed.), Advances in sport psychology. (p. 61-99). Champaign, IL: Human Kinetics.

White, S. A., \& Duda, J. L. 1994. The relationship of gender, level of sport involvement, and participation motivation to task and ego orientation. International Journal of Sport Psychology, 25, 4-18.

White, S. A., Duda, J. L., \& Keller, M. R. 1998. The relationship between goal orientation and perceived purposes of sport among youth sport participants. Journal of Sport Behavior, 21, 474-483.

White, S. A., Kavussanu, M., \& Guest, S. M. 1998. Goal orientations and perceptions of the motivational climate created by significant others. European Journal of Physical Education, 3, 212-228.

Zahariadis, P. N., \& Biddle, S. J. H. 2000. Goal orientations and participation motives in physical education and sport: their relationship in English schoolchildren. Athletic Insight, 2 (1). Retrieved September 29, 2006, from http://www.athleticinsight.com.

(Manuscript received December 6, 2006; Revision accepted August 29, 2007) 